\title{
Geomaterials on the Basis of Analcime-Bearing Rocks
}

\author{
Dmitry A. Shushkov ${ }^{1 *}$, Olga B. Kotova ${ }^{1}$, Boris A. Goldin ${ }^{2}$ \\ ${ }^{1}$ Establishment of Russian Academy of Sciences Institute of Geology of Komi SC UB RAS, Syktyvkar, Russia \\ ${ }^{2}$ Establishment of Russian Academy of Sciences Institute of Chemistry of Komi SC UB RAS, Syktyvkar, Rissia \\ E-mail: dashushkov@rambler.ru
}

Received April 10, 2011; revised May 20, 2011; accepted June 3, 2011

\begin{abstract}
Analcime-bearing rocks (Komi Republic, Russia) are perspective raw for geological materials. The article represents possibilities of their application for water purification, as raw for ceramic industry and poor ore for aluminum industry.
\end{abstract}

Keywords: Analcime-Bearing Rocks, Water Purification, Ion Exchange, Ceramics, Aluminum Extraction

\section{Introduction}

Analcime-bearing rocks (ABR) are wide spread in the Timan region (Komi Republic). By the second half of last century the Timan zeolite-bearing province was determined with the area about $150,000 \mathrm{~km}^{2}$ [1]. The Koinskaya zeolite-bearing area is the most studied, where 10 occurrences of ABR were revealed.

We have studied physical and chemical properties of this raw [2]. The conducted researches resulted in possible directions of use of the rocks as sorbent, raw for ceramic industry and poor ore for aluminum industry.

\section{Materials}

ABR are represented by Upper Permian siltstones and argillites and rare marls. The analysis of mineral composition showed that ABR are characterized by the high content of clay component $(50 \%-70 \%)$, which is saturated by iron oxides and hydroxides. Also quartz $(10 \%-$ $30 \%)$, analcime $(1 \%-30 \%)$, feldspars $(2 \%-10 \%)$, carbonates $(2 \%-5 \%)$, pyroclastic material are present.

In the rocks analcime occurs as isometric crystals, microoolitic concretions, microgeode aggregates or cryptocrystalline cement. Analcime aggregates inlay roundish and oval cavities, and also fill microcracks in the rocks. Different stages of filling of voids by analcime are traced - from insignificant incrustation to complete filling.

The following components are determined chemically (mass.\%): $\mathrm{SiO}_{2}-54-72, \mathrm{TiO}_{2}-0.6-1.1, \mathrm{Al}_{2} \mathrm{O}_{3}-11-18$, $\mathrm{Fe}_{2} \mathrm{O}_{3}-3-8, \quad \mathrm{FeO}-0.2-0.9, \mathrm{MnO}-0.05-0.1, \mathrm{MgO}-$ $0.5-2.3, \mathrm{CaO}-0.6-2.5, \mathrm{Na}_{2} \mathrm{O}-1.4-4.3, \mathrm{~K}_{2} \mathrm{O}-1.4-2.2$, $\mathrm{CO}_{2}-0-0.4$, losses on ignition $-6-9$.

\section{Methods}

\subsection{Preparation of Sorption Material}

The researches on purification of potable water of Vychegda River were conducted. The effect of various kinds of filtering load (ABR with size $-3.0+1.0 \mathrm{~mm}$ and quartz sand) on water treatment process was compared. Comparison of ABR was conducted with quartz sand, not with other sorbents (zeolites), because now quartz sand is used at a local wastewater treatment plant. At the use of ABR without any treatment the permanganate oxidability increased from 3.77 to $9.49 \mathrm{mg} / \mathrm{dm}^{3}$. Therefore further researches were conducted on modified rock, obtained by sintering at temperature $500^{\circ} \mathrm{C}$ within 1 hour. Thermal treatment allowed removing organic substances and increasing sorption properties. The obtained samples were tested on chromaticity, turbidity, iron content and permanganate oxidability.

\subsection{Production of Ceramic Material and Study of Its Properties}

Two types of samples were studied: with analcime from 1 to $5 \mathrm{~mm}$ (sample 1) and "fine-grained"- sizes of analcime inclusions less $1 \mathrm{~mm}$ (sample 2). The samples were prepared by the standard technological scheme. Sintering was made at temperature from $850^{\circ} \mathrm{C}$ to $1250^{\circ} \mathrm{C}$ with step $50^{\circ} \mathrm{C}$. Heat rate $-200^{\circ} \mathrm{C} /$ hour. Exposure at the maximum temperature -2 hours. Cooling occurred in disconnected furnace [3].

Standard characteristics of obtained samples of ceramics were measured: water absorption (W) and open 
porosity $(\mathrm{P})$, flexural strength $(\sigma)$, apparent density $(\rho)$ and linear shrinkage $(\mathrm{g})$.

The properties of the ceramic samples were studied by XFA, DTA, magnetic susceptibility, ultrasonic and acoustic analysis.

\subsection{Aluminum Extraction}

Dealuminization of analcime and ABR was carried out at room temperature by means of hydrochloric and sulfuric acid of various concentration $(2 \%, 3 \%, 4 \%, 5 \%, 7 \%$ and conc.), varied processing time (from 5 minutes to 5 days) and grain size $(-0.05$ and $-0.4+0.2 \mathrm{~mm})$.

Chemical composition of the initial and treated material was defined by means of X-ray fluorescent analysis (MESA500W, Horiba). This analysis is an approximate-quantitative analysis without considering $\mathrm{Na}_{2} \mathrm{O}$ and losses of ignition.

\section{Results and Discussion}

\subsection{Water Purification}

Figures 1-4 show the results of water purification by quartz sand and ABR. Both kinds of filtering load approximately equally improve organoleptic indexes of quality of water (i.e. chromaticity and turbidity decrease). However the ABR much better reduce iron content in water and lower permanganate oxidability [4].

At the choice of post-treatment method of sewage from boiler-houses of Vuktyl gas-processing facility the technological scheme with ABR was considered the most rational for grain load of filter and membrane installation for water desalting [5]. It is proved that purification of waters with the help of ABR is more efficient by many parameters: sorption of iron ions $0.13 \mathrm{mg}$-eqv/100g, amines $10 \mathrm{mg}$-eqv $/ 100 \mathrm{~g}$, magnesium $5.94 \mathrm{mg}$-eqv $/ 100 \mathrm{~g}$, phosphates $1.42 \mathrm{mg}$-eqv/100 g. High adsorptive properties are predicted in relation to oil products and PVA.

The high absorption capacity of uranium $(18.77 \mathrm{mg} / \mathrm{g})$ and sorption durability were determined [6]: distilled water desorbed $1.5 \%$ radio nuclide, $1 \mathrm{M} \mathrm{HCl}-11.5 \%, 1$ $\mathrm{M} \mathrm{CH}_{3} \mathrm{COONH}_{4}-31.2 \%$. ABR sorb from fluid phase $94.0 \%-96.4 \%$ radium.

\subsection{Characteristics of Ceramic Material}

\subsubsection{Behavior at Heating}

As is shown in Figure 5, sintered samples of ceramics represent quartz, feldspars and hematite. In the samples, sintered at $850^{\circ} \mathrm{C}$, there are no diffraction lines of analcime and sterrite. These crystal phases passed to amor-

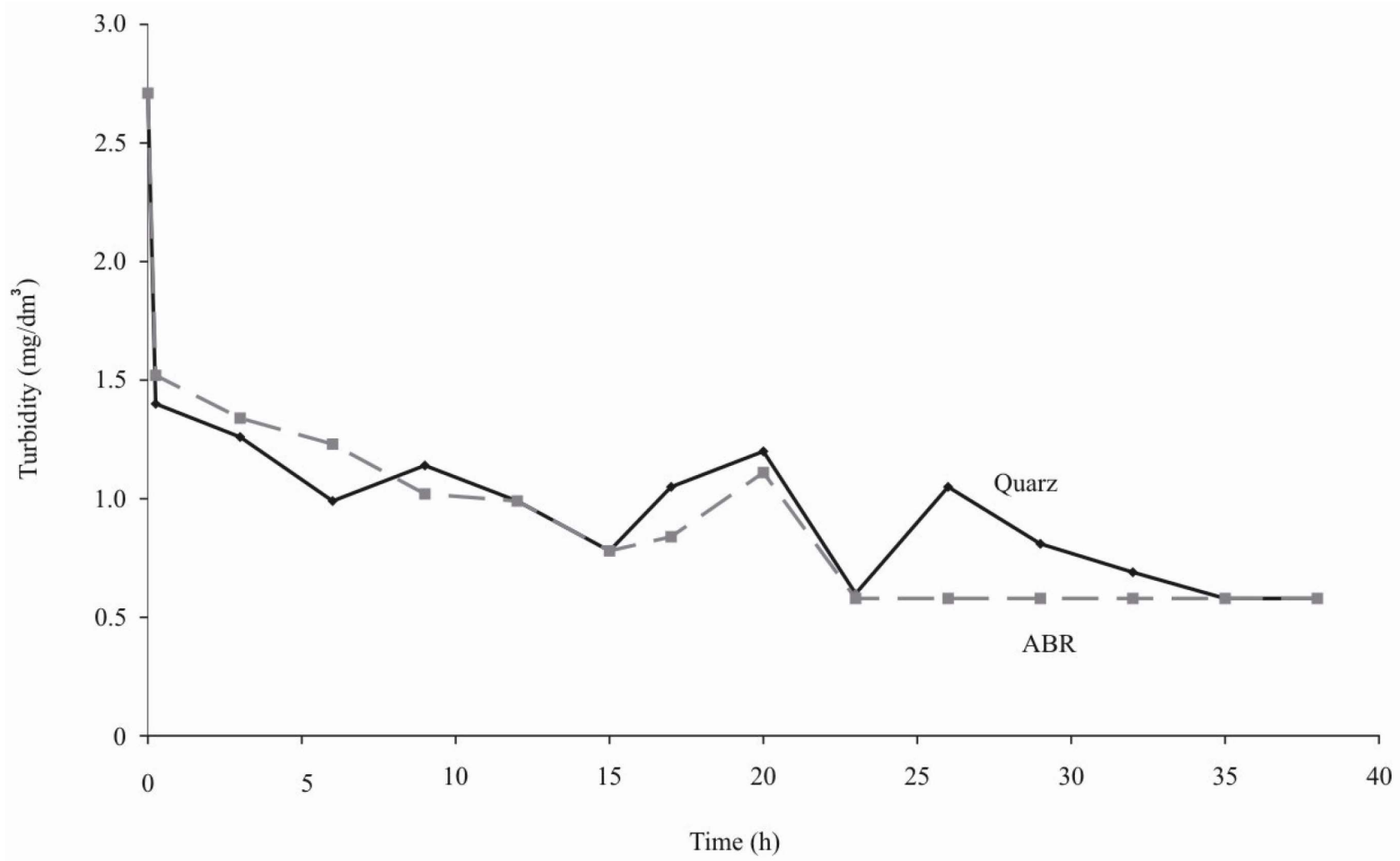

Figure 1. Turbidity of water after purification by ABR and quartz sand. 


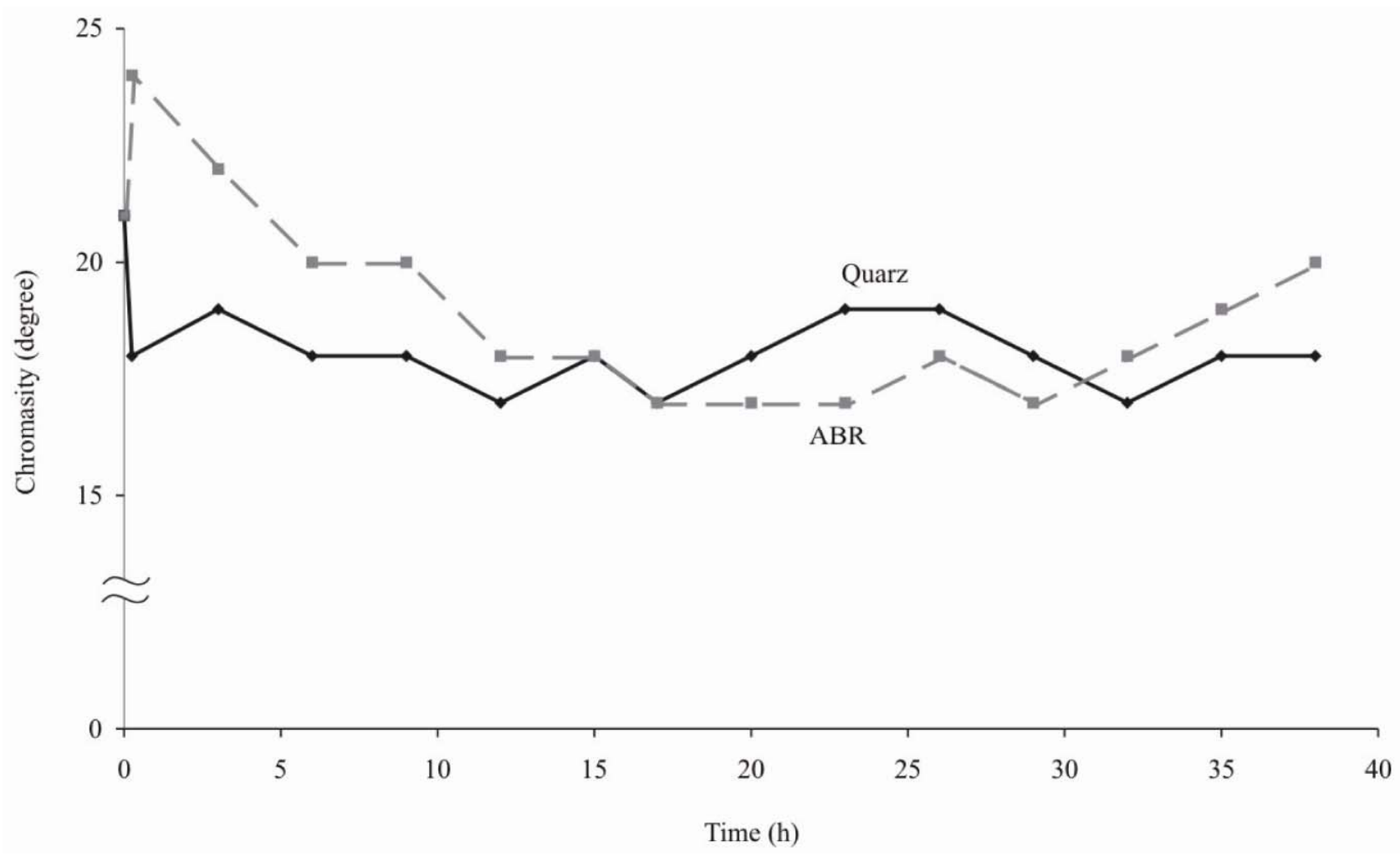

Figure 2. Chromaticity of water after purification by ABR and quartz sand.

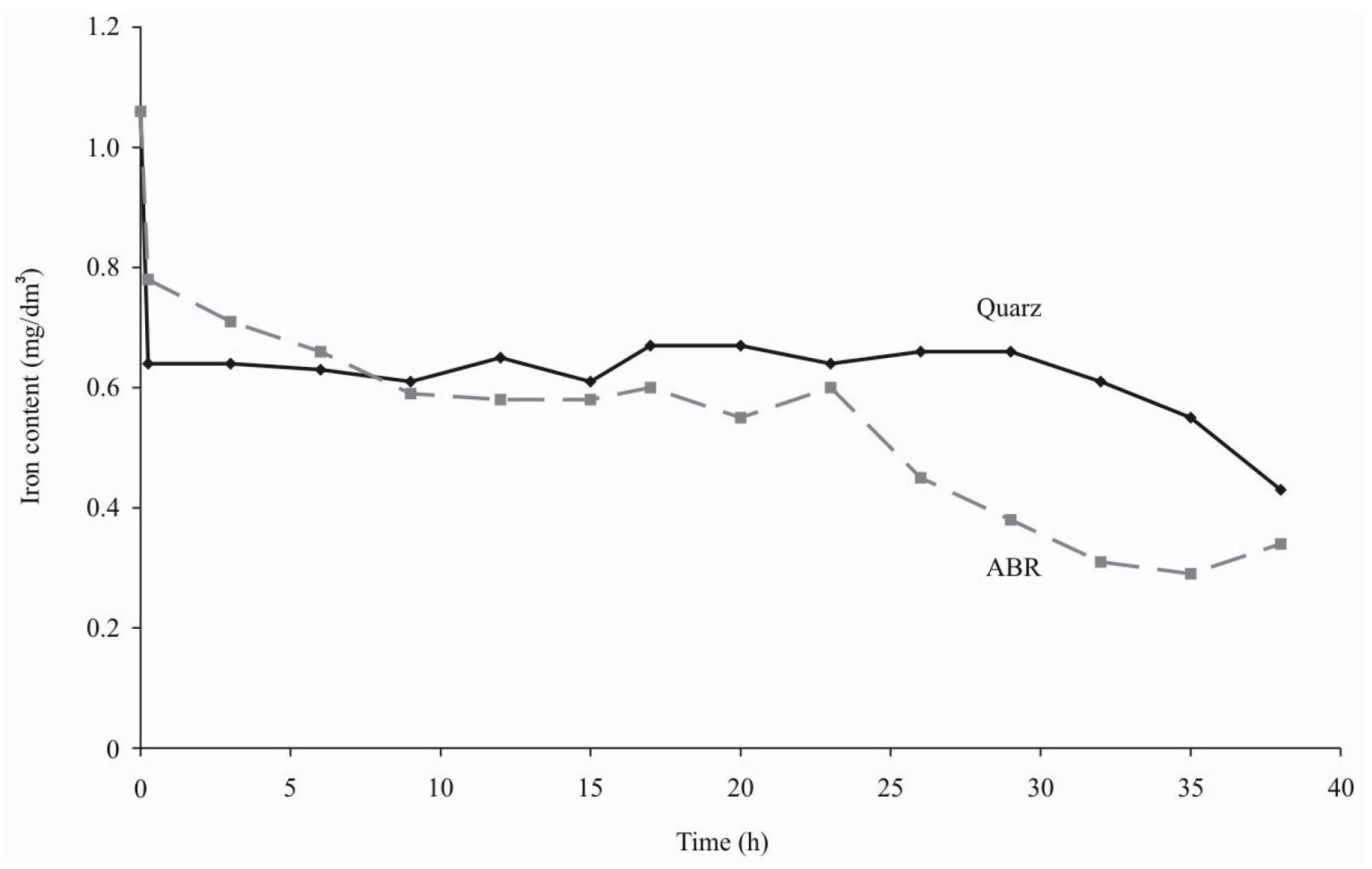

Figure 3. Iron content of water after purification by ABR and quartz sand. 


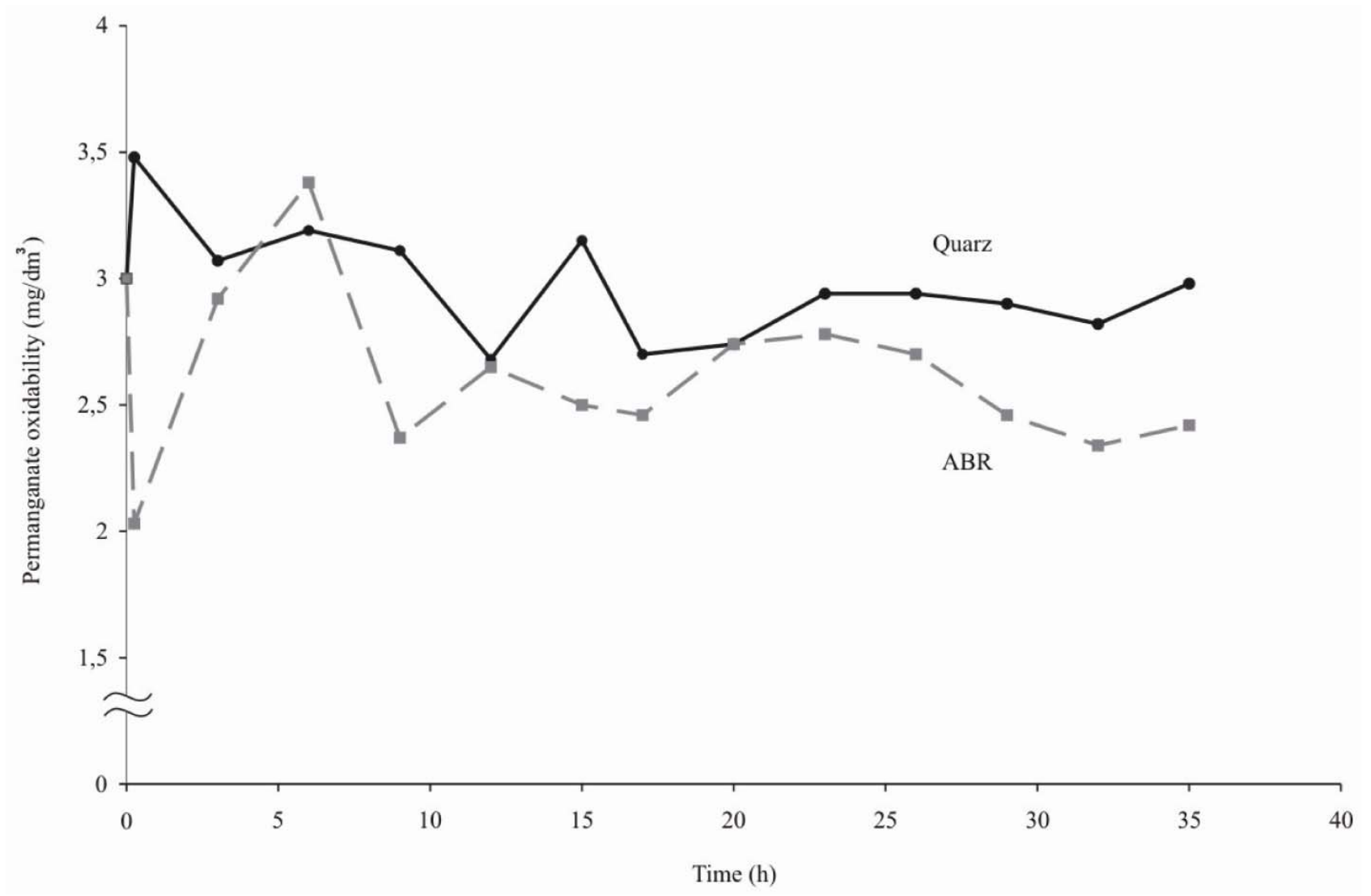

Figure 4. Permanganate oxidability of water after purification by ABR and quartz sand.

phous state.

In the range $900^{\circ} \mathrm{C}-1000^{\circ} \mathrm{C}$ the relative intensity of quartz variates slightly. In sample 2 absolute intensities of lines of quartz were 2 - 3 times more than in sample 1; at higher temperatures the considerable part of quartz passes to glass phase. The relative lines of feldspars monotonously increase with growth of burning temperature, the absolute intensity of their lines in sample 2 are approximately 1.5 - 2 times less in comparison with sample 1. As the absolute intensities of diffraction lines can be generally considered as a measure of quantity of crystal phases in sample, hence, sample 2 contains more quartz and less analcime. Besides, relative intensities of hematite lines increase with increasing burning temperature.

In the range of temperatures $1050^{\circ} \mathrm{C}-1250^{\circ} \mathrm{C}$ almost complete transition of quartz and feldspars to glass phase is observed at conservation of hematite lines and increase of their intensity.

\subsubsection{Water Absorption, Open Porosity, Flexural Strength and Apparent Density}

The conducted experiments showed the following. Firstly, the best interval of sintering was determined-about $900^{\circ} \mathrm{C}$, at that sample 2 had higher hardness in narrow interval of sintering (Figure 6). Secondly, during sinter- ing sample 2 was condensed faster, than sample 1 with formation of almost nonporous material. At the same time sample $1 \mathrm{kept}$ open porosity. Comparing the value of porosity with water absorption (Figure 7) it is possible to draw a conclusion on the ability of molecules of water to enter the material structure, i.e. sample 1 is capable to swell. The surface of sample 2, unlike sample 1, was almost completely vitrified that interferes with infiltration of molecules of water into the material structure. Linear shrinkage appeared proportional to apparent density (Figure 8).

\subsubsection{Acoustic Properties}

Procedures of research of acoustic, electrical and magnetic properties of samples of the received ceramics differ by high rate, accuracy of measurements and are inherently indestructible methods, yielding much richer information on studied objects. Measurements of sound rate $(\mathrm{V})$ yield the information on porosity, hardness and elasticity of the material. Figure 9 shows dependences of $\mathrm{V}$ and ultimate flexure strength $\sigma$ of ceramic materials from temperature of their sintering. Such data allows to judge about reasons of destruction of the sample. If there are fractures, on which the ceramics is destroyed, the dependences $\mathrm{V}(\mathrm{T})$ and $\sigma(\mathrm{T})$ should correlate. Fractures 
slightly affect ultrasonic sound rate, because the delay of acoustic impulse on a fracture is insignificant. At the same time fractures result in decreasing flexural strength. The obtained data (Figure 5) testify to fracture initiation at burning temperatures above $1000^{\circ} \mathrm{C}$, because ultrasonic sound rate changed slightly, but hardness decreased at 3 times.

\subsubsection{Electrical Properties}

Figure 10 presents measurements of electrical properties: dielectric inductivity $(\varepsilon)$ and tangent of dielectric losses $(\tan \delta)$, made at frequencies $1 \mathrm{kHz}$ and $1 \mathrm{MHz}$. At frequency $1 \mathrm{kHz}$ the material polarization can be affected by free ions in ceramics due to its underburning or impurities, for example, adsorption of water vapor. At frequency $1 \mathrm{MHz}$ ion effect is not displayed by measure-

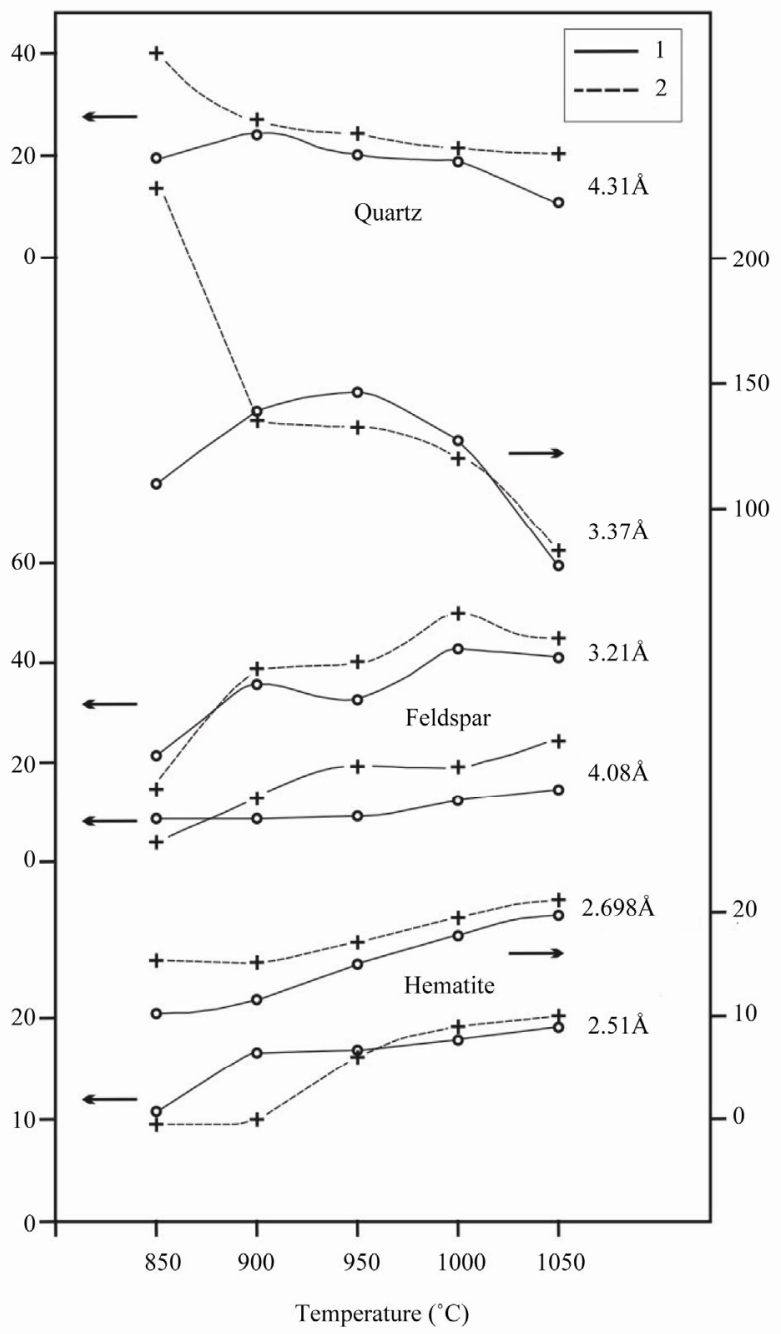

Figure 5. Relative intensity of lines in X-ray pattern versus burning temperature. Corresponding interplanar distances are given on the right.

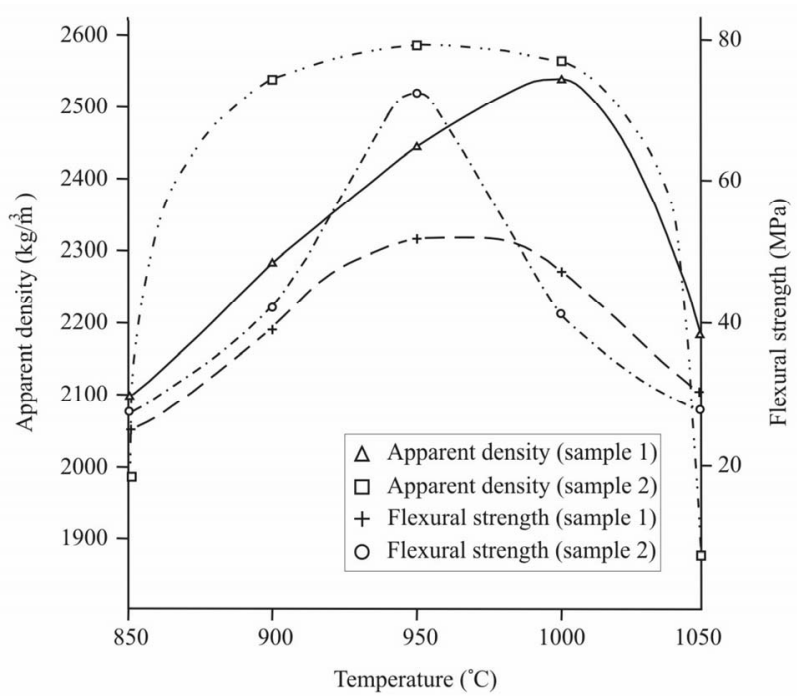

Figure 6. Apparent density $(\rho)$ and flexural strength $(\sigma)$ versus burning temperature $(T)$.

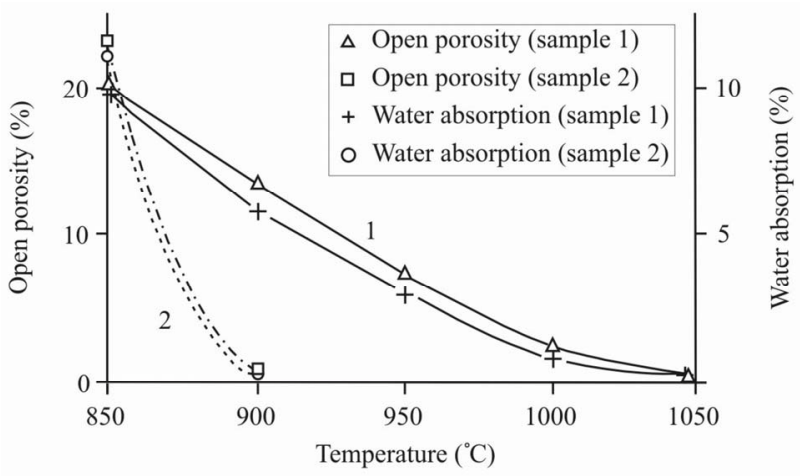

Figure 7. Open porosity (P) and water absorption (W) versus burning temperature $(T)$.

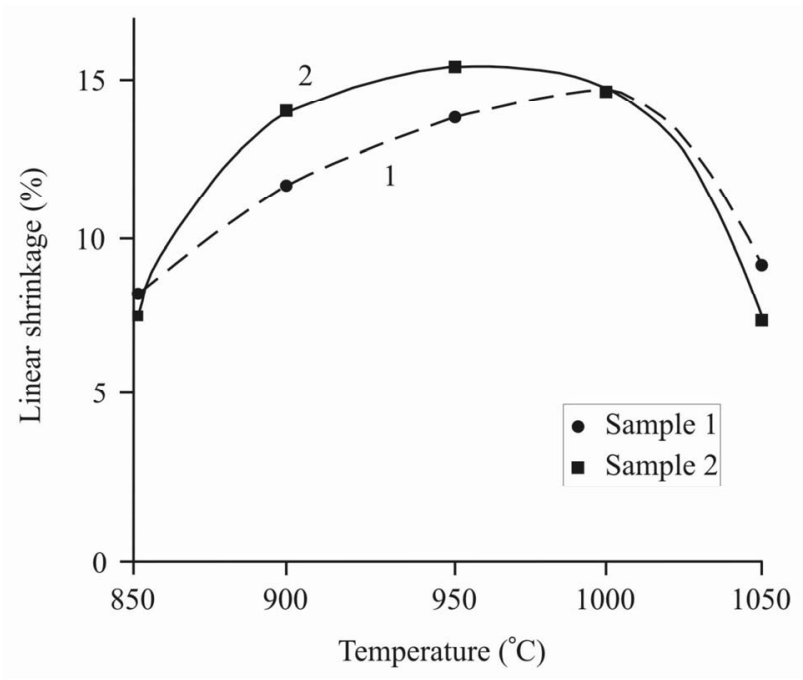

Figure 8. Linear shrinkage (g) versus burning temperature (T). 


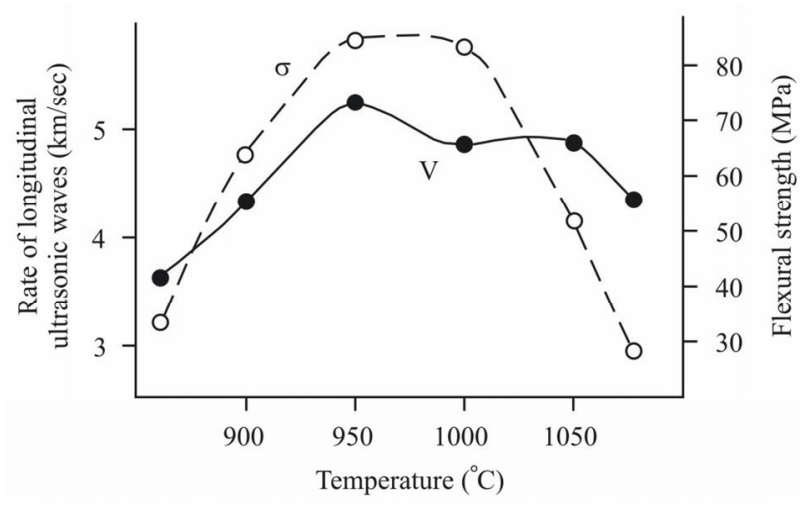

Figure 9. Rate of longitudinal ultrasonic waves (V) and flexural strength $(\sigma)$ of ceramics versus burning temperature (T).
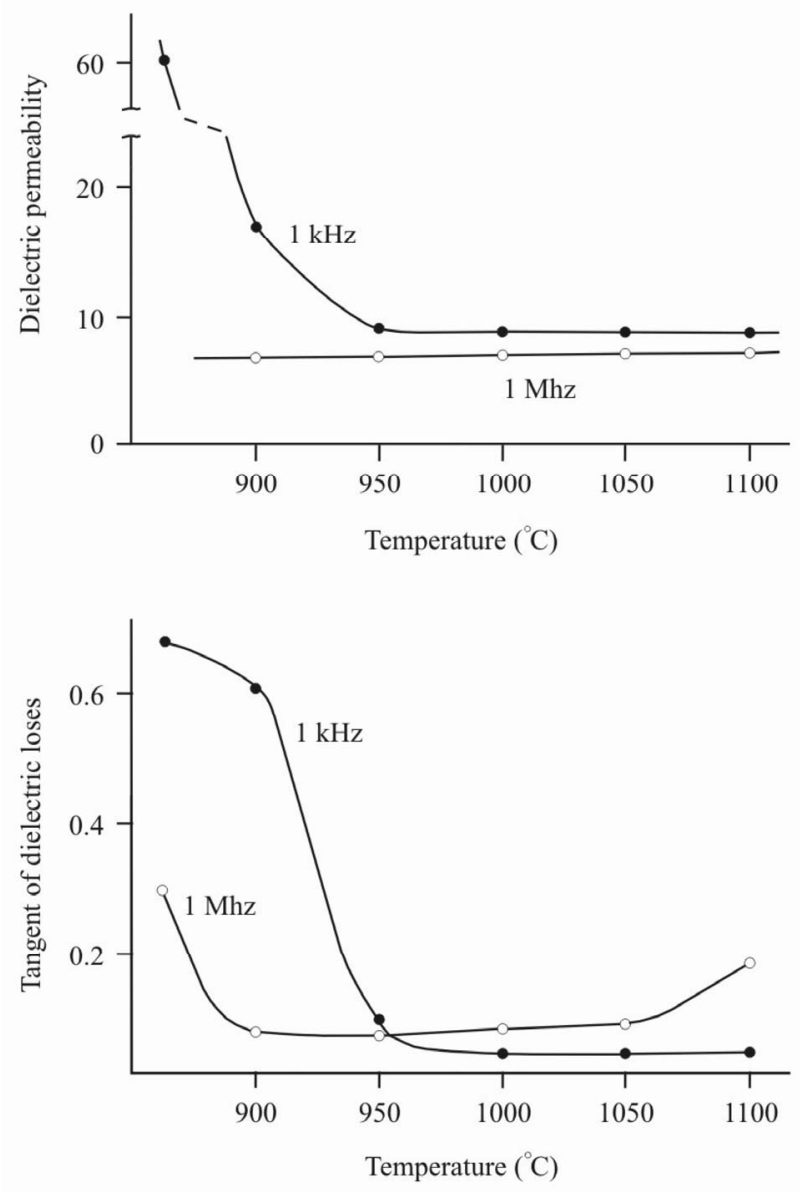

Figure 10. Burning temperature effect $(T)$ on dielectric permeability $(\varepsilon)$ and tangent of dielectric losses $(\tan \delta)$ at frequencies $1 \mathrm{kHz}$ and $1 \mathrm{MHz}$.

ments of $(\varepsilon)$, as the most part of ions doesn't have enough time to drift at any distance. However at $1 \mathrm{MHz}$ the relaxation processes with broken chemical bonds can be registered. It is presented in the growth of tangent of dielectric losses as values characterizing internal friction. Dependences $\varepsilon$ and $\tan \delta$ from burning temperature in Figure 6 speak about the following. Dependence $\varepsilon(T)$ testifies that the satisfactory sintering occurs at temperature not lower $950^{\circ} \mathrm{C}$. Dependence $\tan \delta(\mathrm{T})$ confirms it and, besides, it shows that sintering at temperature above $1050^{\circ} \mathrm{C}$ results in deterioration of electrophysical properties of ceramics.

\subsubsection{Magnetic Properties}

Figure 11 represents the dependence of magnetic susceptibility $(\chi)$ of ceramics samples from burning temperature. The feature of the studied samples is that value $\chi$ corresponds to paramagnetic state, though diamagnetic iron oxides are present at considerable quantity. This can be explained by the presence of hematite crystals in antiferromagnetic or superparamagnetic state. They are preserved until rather high temperatures, a providing very small magnetic susceptibility.

\subsection{Aluminum Extraction}

Analcime is related to framework aluminosilicates; their acid treatment results in dealuminization without destruction of the mineral framework. Ion-exchange capacity increases. The important point is separation of silica and alumina at acid treatment.

Aluminum is included in crystal lattice of both analcime, and clay minerals. Therefore it was interesting to consider not only analcime, but also composing rocks as the source of aluminum.

Table 1 represents results of experiments on extraction of alumina from analcime depending on several parameters: size, acid, its concentration, processing time.

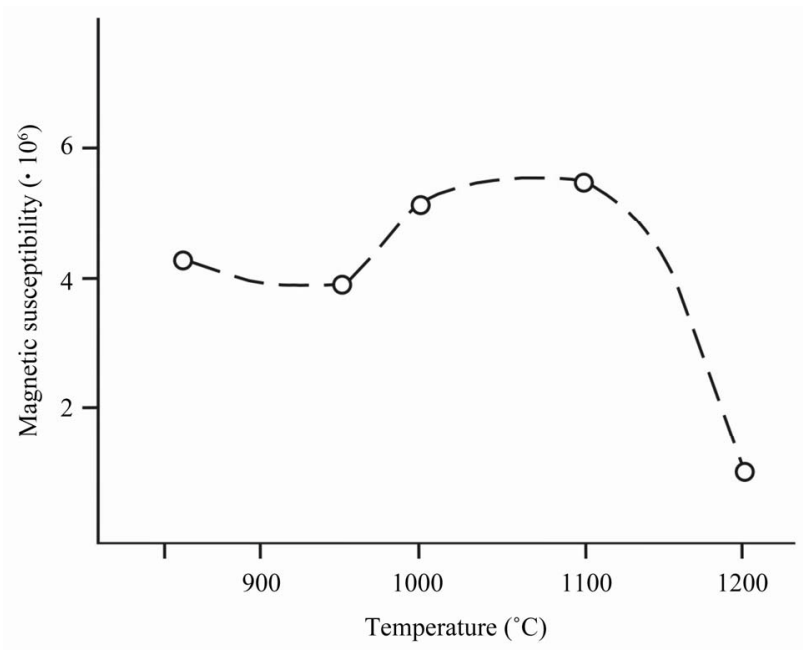

Figure 11. Magnetic susceptibility of ceramics $(\chi)$ versus burning temperature $(T)$. 
Table 1. Change of chemical composition of analcime at treatment by hydrochloric and sulfuric acids.

\begin{tabular}{|c|c|c|c|c|c|c|c|}
\hline Reagent & Concentration & Time, hours & Sample mass, $\mathrm{g}$ & Size, mm & $\mathrm{SiO}_{2}$ & $\mathrm{Al}_{2} \mathrm{O}_{3}$ & $\mathrm{Na}_{2} \mathrm{O}$ \\
\hline \multirow[t]{5}{*}{ Without threatment } & & & & & 66.48 & 19.73 & 13.72 \\
\hline & $2 \%$ & 0.12 & 0.2 & $-0.4+0.2$ & 66.1 & 19.77 & 14.13 \\
\hline & $2 \%$ & 0.5 & 0.2 & $-0.4+0.2$ & 67.05 & 18.81 & 13.59 \\
\hline & $2 \%$ & 72 & 0.1 & $-0.4+0.2$ & 69.69 & 15.7 & 14.61 \\
\hline & $3 \%$ & 72 & 0.1 & $-0.4+0.2$ & 80.4 & 11.1 & 8.5 \\
\hline \multirow[t]{7}{*}{$\mathrm{HCl}$} & $5 \%$ & 24 & 0.1 & -0.05 & 76.47 & 13.48 & 8.17 \\
\hline & $5 \%$ & 120 & 0.1 & -0.05 & 74.03 & 13.49 & 12.41 \\
\hline & $7 \%$ & 0.5 & 0.2 & $-0.4+0.2$ & 69.19 & 18.38 & 12.41 \\
\hline & conc. & 1 & 0.1 & $-0.4+0.2$ & 69.54 & 19.05 & 11.09 \\
\hline & conc. & 48 & 0.1 & $-0.4+0.2$ & 79.88 & 13.63 & 6.41 \\
\hline & $2 \%$ & 0.5 & 0.2 & $-0.4+0.2$ & 69.49 & 19.23 & 10.93 \\
\hline & $10 \%$ & 0.5 & 0.2 & $-0.4+0.2$ & 77.52 & 17.86 & 4.57 \\
\hline \multirow{4}{*}{$\mathrm{H}_{2} \mathrm{SO}_{4}$} & $10 \%$ & 24 & 0.1 & -0.05 & 79.42 & 11.27 & 6.8 \\
\hline & $10 \%$ & 120 & 0.1 & -0.05 & 83.65 & 9.7 & 6.1 \\
\hline & conc. & 1 & 0.1 & $-0.4+0.2$ & 69.2 & 17.44 & 13.28 \\
\hline & conc. & 48 & 0.1 & $-0.4+0.2$ & 71.4 & 16.7 & 11.69 \\
\hline
\end{tabular}

Note: X-ray fluorescent approximate-quantitative analysis without losses of ignition.

Table 2. Change of chemical composition of ABR at treatment by hydrochloric acid.

\begin{tabular}{|c|c|c|c|c|}
\hline \multirow[b]{2}{*}{ Component } & \multicolumn{2}{|c|}{ sample 551} & \multicolumn{2}{|c|}{ sample 58603} \\
\hline & $\begin{array}{l}\text { Without } \\
\text { treatment }\end{array}$ & $\begin{array}{c}5 \% \mathrm{HCl}, \\
120 \mathrm{~h} .\end{array}$ & $\begin{array}{l}\text { Without } \\
\text { treatment }\end{array}$ & $\begin{array}{c}5 \% \mathrm{HCl}, \\
120 \mathrm{~h} .\end{array}$ \\
\hline $\mathrm{SiO}_{2}$ & 55.52 & 61.452 & 63.6 & 62,821 \\
\hline $\mathrm{TiO}_{2}$ & 0.94 & 1.352 & 0.96 & - \\
\hline $\mathrm{Al}_{2} \mathrm{O}_{3}$ & 17.71 & 9.856 & 13.98 & 11.135 \\
\hline $\mathrm{Fe}_{2} \mathrm{O}_{3}$ & 8.91 & 12.478 & 6.17 & 11.332 \\
\hline $\mathrm{MnO}$ & 0.05 & 0.043 & 0.02 & 0.051 \\
\hline $\mathrm{MgO}$ & 1.43 & - & 0.8 & 0.6 \\
\hline $\mathrm{CaO}$ & 0.6 & 0.258 & 2.08 & 1.327 \\
\hline $\mathrm{K}_{2} \mathrm{O}$ & 1.36 & 1.085 & 1.55 & 2.456 \\
\hline $\mathrm{P}_{2} \mathrm{O}_{5}$ & 0.07 & 0.087 & 0.79 & 0.052 \\
\hline $\mathrm{Cr}_{2} \mathrm{O}_{3}$ & 0.02 & 0.036 & 0.01 & 0.017 \\
\hline $\mathrm{NiO}$ & 0.01 & - & - & - \\
\hline $\mathrm{ZnO}$ & 0.01 & - & - & - \\
\hline $\mathrm{Rb}$ & 0.01 & - & 0.01 & 0.009 \\
\hline $\mathrm{Sr}$ & 0.01 & - & 0.02 & - \\
\hline
\end{tabular}

Copyright (C) 2011 SciRes.
As a result the extraction of $\mathrm{Na}_{2} \mathrm{O}$ was from $1.0 \%$ to $66.7 \%$, extraction of $\mathrm{Al}_{2} \mathrm{O}_{3}-4.7-50.8 \%$. The greatest extraction of alumina was achieved after treatment by $3 \% \mathrm{HCl}$ within $72 \mathrm{~h}$ and $10 \% \mathrm{H}_{2} \mathrm{SO}_{4}$ within 24 and $120 \mathrm{~h}$. More than $30 \%$ of alumina were extracted to solution after treatment by concentrated hydrochloric acid within $48 \mathrm{~h}$ and $5 \% \mathrm{HCl}$ within 24 and $120 \mathrm{~h}$.

Table 2 shows the change of chemical composition of 2 samples of analcime clay rocks. The content of alumina after treatment of sample 551 decreased at $44.4 \%$, sample 58,603 - at $20.4 \%$. Besides, in the samples the content of $\mathrm{CaO}$ and $\mathrm{MgO}$ and also $\mathrm{K}_{2} \mathrm{O}$ in one hallmark decreased.

\section{Conclusions}

On the basis of authors' researches and other data it should be noted that ABR of Timan can be applied in various spheres of economic activity. For example, as a filtering material at purification of economic potable water in fast filters instead of quartz sand. Low silica zeolites including analcime (and also ABR) can be considered as poor raw for aluminum industry, with passing production of silica and natrium products. Besides, the application of the given rocks for building and electro- 
technical ceramics is promising.

\section{Acknowledgements}

This work was funded by grant No 09-C-5-1022.

\section{References}

[1] B. A. Ostashchenko, "Problem of Zeolites of the Timan region," Scientific Recommendations for National Economy/Komi Science Center UB RAS, No. 49, 1984, Rotaprint, Syktyvkar, 20 Pages (in Russian).

[2] D. A. Shushkov, O. B. Kotova, V. M. Kapitanov and A. N. Ignatyev, "Analcime-Bearing Rocks of Timan as Perspective Type of Minerals," Scientific Recommendations for National Economy/Komi Science Center UB RAS, No. 123, 2006, Rotaprint, Syktyvkar, 40 Pages (in Russian).
[3] B. A. Goldin, D. N. Grishin, I. V. Klochkova, L. N. Kotov, Yu. I. Ryabkov, N. A. Sekushin and N. A. Tikhonov, "Ceramics on the Basis of Analcime-Bearing Rocks," Scientific Recommendations for National Economy/ Komi Science Center UB RAS, No. 108, 1994, Rotaprint, Syktyvkar, 12 Pages (in Russian).

[4] D. A. Shushkov, O. B. Kotova and I. P. Palshin, "Method of Water Purification," Russian Patent 2296718, 2007.

[5] T. D. Lanina and B. G. Varpholomeev, "Application of Natural Zeolite for Additional Purification of Sewage from Boiler-Houses of Vuktyl Gas Complex," Building of Oil and Gas Boreholes on Land and sea, No. 8, 2007, pp. 38-40 (in Russian).

[6] N. G. Rachkova and I. I. Shuktomova, "Role of Sorbents in Processes of Transformation of Bonds of Uranium, Radium and Thorium, in Podsolic Soil," Nauka, St. Petersburg, 2006, 146 Pages (in Russian). 